and Ms. Monika Ciüntner and Ms. Claudia Wohlfarth for the fauleles technical atsistance.

35. This work was supported by Deutsche Forschungsgemeinschaft (SFBB 147)

36. Requests for reprints should be addressed to: O. Linderkamp. M.J). Univer- sitatshinderklinik, Lindwurmstr. 4, D)-8 Munich 2 (Federal Republic of (iermany).

37. Received for publication November, 15. 1976

38. Accepted for publication I)ecember $21,1976$.
Adrenalino

asphyxia

catecholamines fetus

heart rate

noradrenaline

\title{
Catecholamine Release in the Newborn Infant at Birth
}

\author{
IIUG() LAGIERCRANTZ!3: ANI) PETIER BISTOI.I:ITI \\ Department of Physiology, Karolinska Institute, Stockholm, and Departments of Pediatrics and Obstetrics and \\ Gynecology', Karolinska lnstitute'. Hudding'e Hospital, Huddinge', Swe'de'n
}

\section{Summary}

Catecholamines were determined by a fluorimetric technique in umbilical blood which was collected from newborn infants immediately after birth. The mean catecholamine concentration was $62.1 \mathrm{nmol} /$ liter in the umbilical artery and $29.3 \mathrm{nmol} / \mathrm{liter}$ in the umbilical vein of newborn full term infants delivered uneventfully. This value is considerably higher than in resting adults. Similar levels of catecholamines were seen after elective cesarean sections, whereas considerably higher levels were found after breech deliveries. In the full term asphyxiated infants about a 4 -fold increase of the eatecholamine concentration was found in both the umbilical arterial and venous blood. The amine concentration level correlated inversely to the pll below 7.25 ("Iog catecholamine concentration versus pll, $r=-\mathbf{0 . 7 1}$ ). Preterm infants had, in general, lower amine levels than full term infants both after uneventful deliveries and after intrauterine asphyxia. The catecholamine levels were considerably increased in the newborn infants who showed some kind of alonormal fetal heart rate variation during the last hour before birth; in particular baseline changes were associated with high levels whereas only a moderate increase was seen after loss of beat-to. beat variation.

\section{Speculation}

The high catecholamine concentrations in umbilical blood, seen even after uneventful deliveries, indicate that the sympathoadrenal system might have a functional role in the fetus at delivery. The enomous levels at asphyxia might be of importance to sustain the circulatory homeostasis.

The sympathoadrenal system is certainly of great importance for the regulation of the fetal heart rate during delivery. Determination of catecholamines (preferably in scalp blood samples) can be a valuable tool in the study of cardiotocography.

Studies on fetal sheep have demonstrated that adrenergic cardiovascular control is well developed at term $(11,19.23)$. Probably there are fewer noradrenaline stores in the sympathetic nerve terminals of the fetus compared with the adult (11); on the other hand. there are increased catecholamine stores in the adrenal medulta per kg body weight (7) and possibly also in the paraganglia. The isolated fetal heart is more sensitive to catecholamines than the adult heart; this supersensitivity has been compared to that of the denervated organ (11). These findings indicate that the circulating catecholamines may play a greater role in the fetus than in the adult (11). Hypoxia induces a large increase of the catecholamine secretion from the adrenal medulla (15). Even during moderate hypoxia (fetal arterial po.

$18 \mathrm{~mm} \mathrm{Hg}$ during $1 \mathrm{hr}$ ) more than 10 -fold increase of the catecholamine concentration in plasma was found. Catecholamines administrated to the fetal sheep in similar concentrations to these released during mild hypoxiat were found to cause large cardiovascular effects (21).

On the basis of the findings in fetal sheep this study was performed to investigate the sympathoadrenal activity in the human newborn. Catecholamines were determined in umbilical blood and the levels were correlated with signs of fetal hypoxia such as $A$ pgar seore and hlood gases. Particular interest was paid to the problem of whether there wals any relation between the cattecholamine level and abnormat fetal heart rate patterns before birth.

\section{MATERIALS ANI) METHODS}

Plasma catecholamines were determined in a number of newborn infants delivered at Huddinge Hospital. The infants were classificd in various groups according to clinical conditions (group $A$ ) and according to fetal heart rate patterns (group $B$ ).

\section{GROUP A: CLINICAI CONDITIONS CLASSIFICATION}

Group i: Full Term Infants Delivered Uneventfilly. All of these cases were delivered vaginally in vertex position; their fetal heart rate patterns were found to be essentially normal (sec below) and their Apgar scores were above 7 at 1 min. The infants in this group hat a gestational age of 37-4.3 weeks and were appropriate in weight for gestational age.

Group ii: Preterm Infimts Delivered Une'ventully. These infants fulfilled the same conditions as above. except that the gestational age was less than 37 weeks.

Group iii: Infants Delivered by Elective Cesarean Section. Maternal indications such as small pelvis, long steritity, and the 
psychological reasons were cause for cesarean section. All of these infants were full term and appropriate in weight for gestational age. As anesthetic agent propanedidid (Epontol, Bayer), about $400 \mathrm{mg}$, was used. Succinylcholine $(100 \mathrm{mg})$ was used as relaxant.

Group iv: Infants Delivered in Breech Position. These infants were full term and appropriate in weight for gestational age.

Group v: Asphyiated Full Term Infants. These were infants with an Apgar score of less than 7 at $1 \mathrm{~min}$ and gestational age of more than 36 weeks.

Group vi: Asphyxiated Preterm Infants. Infants with an Apgar score of less than 7 at $1 \mathrm{~min}$ and gestational age of less than 37 weeks were in this category.

\section{GROUP B: FETAL HEART RATE PATIERN CLASSIFICATION}

Infants were also classified according to predominant fetal heart rate pattern during the last hour before delivery. Most of the uneventful cases above were also included in these groups. The fetal heart rate patterns were interpreted visually essentially according to the criteria of Hon (14).

Group i: Normal Pattern. This was defined as a fetal heart rate between 120 and 150 ; normal beat-to-beat variation (more than $5 / \mathrm{min})$; and the absence of late decelerations and severe variable decelerations. Accelerations, early decelerations, and moderate variable decelerations in the absence of baseline changes were accepted as normal ( $c f$. References 1 and 20).

Group ii: Bradycardia. This was established as a baseline fetal heart rate below 120 for at least $10 \mathrm{~min}$ as the predominant pattern.

Group iii: Tachycardia. Tachycardia was defined as a baseline fetal heart rate above 150 at least 10 min.

Group iv: Loss of Beat-to-beat Variation. A fetal heart rate variation of 5 or less per min was the criterion. Complicated loss of beat-to-beat variation ( $c f$. Reference 1 ) with baseline changes and/or variable decelerations was included in this group.

Group v: Late Deceleration Pattern. This was defined as three subsequent decelerations developed after the peaks of the uterine contractions. Fetuses with other abnormal fetal heart rate patterns besides the late decelerations were nevertheless classified as late deceleration pattern, since this was regarded as the predominant most severe pattern ( $f$. Reference 6 ).

\section{MONITORING}

Fetal heart rate was continuously monitored with a scalp electrode connected to a Corometrics cardiotocograph (27). The intraterine pressure was recorded by an intrauterine catheter. The Apgar score was routinely determined by the midwife in charge and, in the asphyxiated cases, usually by the pediatrician in charge. The gestational age was determined in doubtful cases according to the classification system of Dubowitz (10).

\section{CHEMICAL ANALYSES}

The umbilical cord was clamped at the infant and placental end before the first breath. Umbilical arterial and also, in many cases, venous blood was drawn into prelubricated. heparanized. sterile plastic syringes. An aliguot of the arterial blood was used for determination of the blood gases. Often it was not possible to obtain enough arterial blood for both blood gases and the catecholamine assay, so that only venous catecholamines were determined. In some cases, particularly in the beginning of the study and during the nights, only mixed umbilical blood was obtained. This probably consisted mainly of venous blood and was classified as such.

The blood was collected in prechilled tubes which were centrifuged for $10-15 \mathrm{~min}$ at $3000 \mathrm{rpm}$. The plasma was sucked off; the proteins were usually removed before freezing the samples by the addition of perchloric acid to a final concentration of 0.4 M. The samples were analyzed a few days after they had been obtained.
After thawing, the protein precipitate was removed by centrifugation and the supernatant was titrated to pH 4 with $\mathrm{NaOH}$. The samples were frozen again briefly to precipitate the perchlorate, than titrated to pH 8 and applied to small glass columns with alumina oxide (28) which was carefully washed before use. The columns were rinsed with distilled water until the effluent became neutral; this was checked with $\mathrm{pH}$ papers. The amines were eluated with $2 \times 0.5 \mathrm{ml}$ acetic acid, $0.3 \mathrm{M}$.

The oxidation of catecholamines was performed essentially according to the method of Chang (4). A 250- $\mu$ l portion of the eluate was oxidized with $30 \mu \mathrm{l}$ iodine $(0.1 \mathrm{M}$ in ethanol); the reaction was interrupted after exactly $2.5 \mathrm{~min}$ with 500()$\mu l$ freshly made sodium bisulfate solution (0.2 $\mathrm{M}$ in $5 \mathrm{M} \mathrm{NaOH})$; after 2 min more $500 \mu \mathrm{l}$ acetic acid $(5 \mathrm{M})$ were added. To stabilize the fluorophores the samples were boiled for $2 \mathrm{~min}$. The noradrenaline fluorescence was read at $380 \mathrm{~nm}$ and $480 \mathrm{~nm}$ and the adrenaline fluorescence at $420 \mathrm{~nm}$ and $510 \mathrm{~nm}$ in an Aminco-Bowman spectrofluorometer (29). Small cuvettes (J48137), 0.15-0.8 ml, were used. (29).

Standard amounts of noradrenaline and adrenaline were added to aliquots of plasma samples at the delivery ward. The mean recovery of the noradrenaline standard was $+2.4 \pm 1.9 \%$ $(\mathrm{SEM}, n=9)$ and of the adrenaline standard $38.0 \pm 1.8 \%(n=$ $5)$. The recovery of noradrenaline from the alumina columns was found to be $56.9 \pm 2.6 \%(n=14)$ and of adrenaline $52.1 \pm$ $1.8 \%(n=5)$. Thus about $14 \%$ of the losses occurred during storage before the analyses started. All values have subsequently been corrected for the total losses.

The sensitivity of the fluorescence assay was about 2 nmol of noradrenaline or adrenaline ( $=2 \mathrm{SD}$ of the blanks). Because of the overlapping of the fluorescence spectra of the two catecholamines, the noradrenaline and adrenaline values had to be calculated by simultancous equations (26). Since the noradrenaline concentration was generally considerably higher than the adrenaline concentration, small amounts of adrenaline could not be detected.

Arterial blood gases were analyzed with a Radiometer BMS (30). Two determinations were routinely performed.

\section{RISULTS}

The results of the catecholamine analyses in the umbilical blood of the infants classified according to clinical criteria are summarized in Table 1 . The full term infants delivered uneventfully had normal fetal heart rate patterns according to definition and a mean Apgar score of 8.5 after 1 min. Their mean catecholamine concentration in the umbilical arterial blood was 62.1 $\mathrm{nmol} / \mathrm{liter}$ plasma and in the venous blood $29.3 \mathrm{nmol} / \mathrm{liter}$. Only $16 \%$ of the total catecholamines was found to be adrenaline. Preterm infants delivered without complications had lower catecholamine concentrations than the corresponding full term infants. However, there were only a few preterm infants with normal fetal heart rate pattern and without asphyxia, which is why the difference was not significant.

Full term infants delivered by elective cesarean section had essentially the same mean catecholamine concentrations in both the arterial and venous umbilical blood as the full term infants delivered vaginally and uneventfully.

Infants delivered in breech position had considerably higher catecholamine concentrations than the normal cases: 6.3-fold higher in the arterial and 3.2-fold higher in the venous blood. The mean Apgar score was 6.7; only one infant had a seore below 3 at $1 \mathrm{~min}$.

The asphyxiated infants were also found to have considerably increased catecholamine concentrations than the uneventful cases, but lower than the breech cases. The asphyxiated preterm infants had generally lower plasma catecholamine concentrations than the asphyxiated full term infants. A successive increase at increasing gestational age in amine secretion due to asphyxia can be seen in Figure 1. (One exception was a severely asphyxiated fetus delivered in the 27 th week with high amine 
Table 1. Mean catecholamine (CA) concentrations (SEM) in umbilical arterial and venous blood at various clinical conditions

\begin{tabular}{|c|c|c|c|c|c|c|}
\hline & $\begin{array}{c}\text { CA }_{\text {irterial }} \\
\text { nmol/liter }(n)\end{array}$ & $\begin{array}{c}\text { CA }_{\text {venous, }} \\
\text { nmol/liter }(n)\end{array}$ & $\begin{array}{c}\text { Adrena- } \\
\text { line, } \% \\
\text { of } \mathrm{CA}\end{array}$ & $\begin{array}{c}\text { Apgar score at } 1 \\
\min (n)\end{array}$ & $\begin{array}{c}\left(\mathrm{H}^{+}\right) \\
\text {nmol/liter }(n)\end{array}$ & $\mathrm{pH}$ \\
\hline Uneventful (full term) & $62.1 \pm 9.3(15)$ & $29.3 \pm 2.7(24)$ & 16 & $8.5 \pm 0.2(33)$ & $52.7 \pm 1.2(18)$ & 7.28 \\
\hline Uneventful (preterm) & $37.8 \pm 1.8(5)$ & $18.0 \pm 0.5(6)$ & 12 & $8.0 \pm 0.3(6)$ & & \\
\hline $\begin{array}{l}\text { Elective cesarean sections } \\
\quad \text { (full term) }\end{array}$ & $69.2 \pm 10.1(12)$ & $30.6 \pm 10.7(9)$ & 19 & $7.7 \pm 0.4(13)$ & $52.3 \pm 1.3(7)$ & 7.28 \\
\hline $\begin{array}{l}\text { Breech deliveries (full } \\
\text { term) }\end{array}$ & $369.0 \pm 152.0^{1}(6)$ & $91.8 \pm 17.1^{1}(9)$ & 10 & $6.7 \pm 0.6^{1}(15)$ & $61.4 \pm 3.2^{1}(5)$ & 7.21 \\
\hline Asphyxia (full term) & $218.2 \pm 6.3 .6^{1}(13)$ & $118.8 \pm 22.5^{1}(20)$ & 13 & $4.5 \pm 0.8^{1}(26)$ & $70.4 \pm 5.14^{\prime}(16)$ & 7.15 \\
\hline Asphyxia (preterm) & $115.2 \pm 25.3^{1}(5)$ & $56.0 \pm 18.7^{\prime}(10)$ & 13 & $4.2 \pm 0.6^{1}(11)$ & $61.3 \pm 9.0(9)$ & 7.21 \\
\hline
\end{tabular}

'Significantly different from the uneventful cases $(P<0.01)$ according to Student's $t$-test.

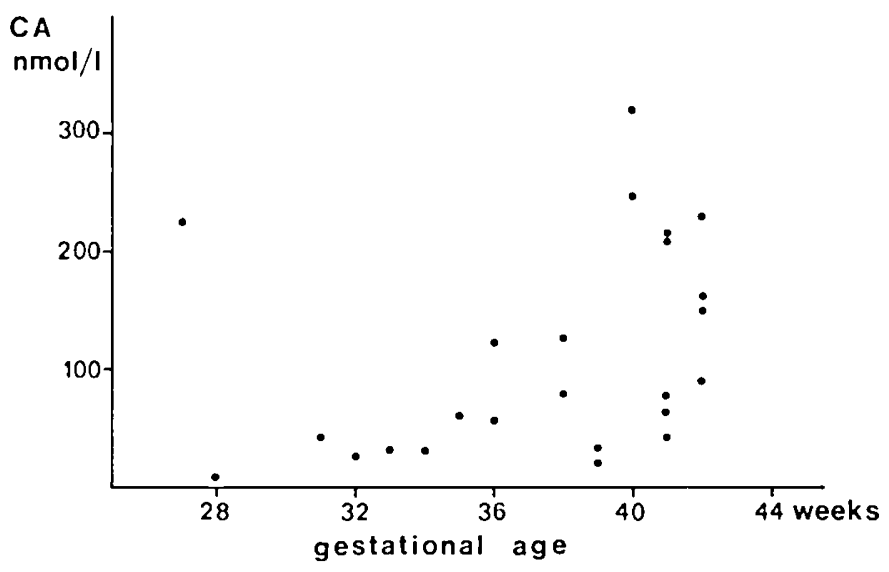

Fig. 1. Catecholamines $(C A)$ in umbilical venous blood against gestational age in asphyxiated infants (Apgar score $<7$ at $1 \mathrm{~min}$ ).

concentrations, possibly because the mother had received the $\beta$ receptor stimulating drug, salbutamol, to prevent labor.)

The arterial catecholamine concentrations were compared with the $\mathrm{pH}$ in the umbilical arterial blood (Fig. 2). A number of infants had increased amine concentrations without being acidotic, but below pH 7.25 there was an inverse correlation between the "log of the arterial catecholamine concentration and pH $(r=-0.71)$. The correlation coefficient between arterial $\mathrm{pO}_{2}$ and arterial amine concentration was only -0.45 .

The catecholamine concentrations in umbilical arterial and venous blood were correlated to the predominant fetal heart rate pattern during the last hour before delivery without any regard to gestational age and other clinical circumstances. The results are shown in Table 2.

Fetuses with normal pattern had a mean catecholamine concentration of 59.2 nmol/liter in umbilical arterial blood and 29.1 in the venous blood. Their mean Apgar score was 8.5 ; only 2 infants of 35 had an Apgar score below 7 at 1 min and only 2 had more than 2 SD of catecholamines than the mean (Fig. 3).

Infants who had bradycardia before delivery had considerably increased plasma catecholamine concentrations (62\% had more than 2 SD) and were often asphyxiated (46\%). One infant with a gestational age of about 43 weeks was found to have exceptional high amine concentrations; $620 \mathrm{mmol} / \mathrm{liter}$ in the arterial and $148 \mathrm{nmol} / \mathrm{liter}$ in the venous blood. The bradycardia appeared directly after paracervical blockade with $25 \mathrm{mg}$ bupivacain. The infant was delivered in $20 \mathrm{~min}$ by cesarean section and then had an Apgar score of 2 at $1 \mathrm{~min}$ and $\mathrm{pH} 7.01 \mathrm{in}$ umbilical arterial blood.

Fetuses with tachycardia had the highest catecholamine concentrations of all the groups classified according to fetal heart rate patterns 4 -fold higher than the mean normal level in the venous blood. Arterial blood was collected only in four cases; one of these had an arterial concentration of 940 nmol/liter, but in spite of that had an Apgar score of 7 . The $\mathrm{pH}$ was 7.09.

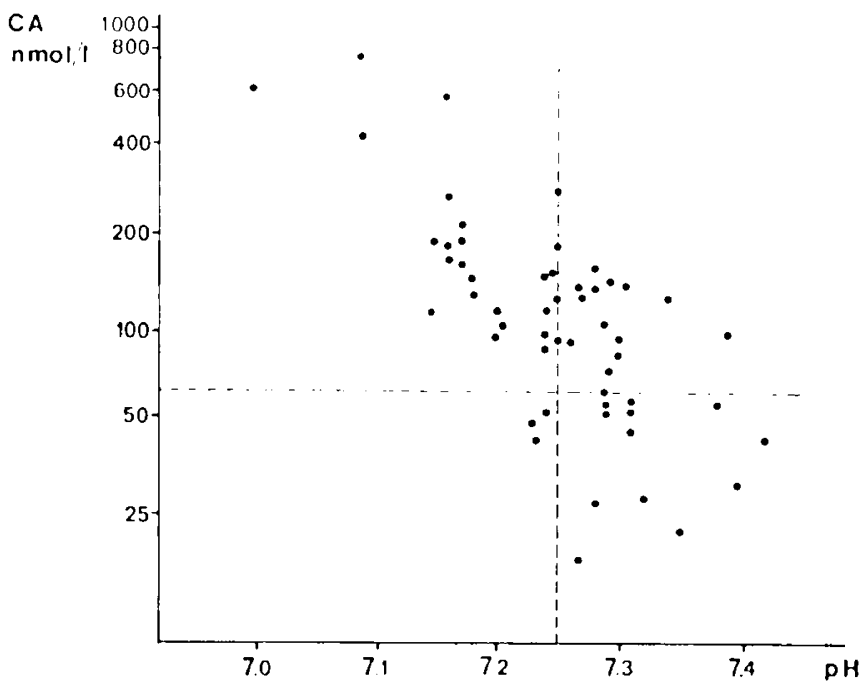

Fig. 2. Arterial catecholamines ("log) against arterial pH. Below pH 7.25 the correlation coefficient $=-0.71$. The mean arterial catecholamine concentration in the uneventful cases is indicated by the horizontal dashed line.

Although $85 \%$ of all the fetuses in this group had more than 2 SI) of catecholamines than the normal infants, only $3.5 \%$ were asphyxiated (Fig. 3).

Fetuses who showed loss of beat-to-beat variation were found to have increased plasma amine levels when delivered compared with those with normal pattern, but lower than those with only baseline changes. The mean Apgar score was, however, about the same 6.6 as those with other abnormal fetal heart rate patterns. Six of 20 fetuses with this pattern were asphyxiated when delivered, but only 2 of these had increased amine levels (more than $2 \mathrm{SD}$ ).

Fetuses with late decelerations had the highest incidence of asphyxia when delivered (Fig. 3). Their mean amine level in umbilical venous blood was 4 -fold higher than those with normal patterns.

\section{DISCUSSION}

Catecholamines have been determined in the umbilical arterial and venous blood of the newborn infant as a parameter of fetal distress. Catecholamines pass the placenta easily and the possibility of maternal influence has to be considered. Our own studies and earlier observations indicate, however, that this influence is neglible: ( 1 ) The catecholamine level was found to be considerably higher in the newborn than in the mother and no correlation between maternal and fetal catecholamine levels could be detected ( $c f$. Reference 13). (2) The placenta has an extremely high monoamine-oxidase activity and the catecholamines are rapidly metabolized (24). Only $10-12 \%$ of tritiumlabeled noradrenaline injected into the mother (during abortion by sectio parva in the second trimester) was found as intact 
Table 2. Mean catecholamine (CA) concentrations ( \pm SEM) in umbilical arterial and venous blood versus pre'dominant fe'tal heart rate pattern

\begin{tabular}{|c|c|c|c|c|c|c|c|}
\hline & $\begin{array}{l}\text { Gestational } \\
\text { age, weeks }\end{array}$ & $\begin{array}{c}\text { CA }_{\text {:trterial }} \\
\text { nmol/liter }(n)\end{array}$ & $\begin{array}{c}\text { CAvenous } \\
\text { nmol/liter }(n)\end{array}$ & $\begin{array}{l}\text { Adrena- } \\
\text { line, } C^{\prime} \\
\text { of } \mathrm{CA}\end{array}$ & $\begin{array}{c}\text { Apgar score at } 1 \\
\min (n)\end{array}$ & $\left(\mathrm{H}^{+}\right), \mathrm{nmol} / \mathrm{liter}$ & $\mathrm{pH}$ \\
\hline Normal pattern & $39.4 \pm 0.4$ & $59.2 \pm 9.2(18)$ & $29.1 \pm 3.0(26)$ & 16 & $8.5 \pm 0.2(35)$ & $52.4 \pm 1.2(18)$ & 7.28 \\
\hline Bradycardia & $40.6 \pm 0.3$ & $289.3 \pm 103.0^{1}(6)$ & $94.0 \pm 20.8^{1}(12)$ & 14 & $6.6 \pm 0.7^{\prime}(1.5)$ & $69.5 \pm 8.4^{\prime}(8)$ & 7.16 \\
\hline Tachycardia & $39.8 \pm 0.9$ & $379.9 \pm 36.3^{1}(4)$ & $116.6 \pm 29.4^{1}(8)$ & 16 & $6.5 \pm 0.9^{1}(10)$ & $63.0 \pm 6.9(4)$ & 7.21 \\
\hline $\begin{array}{c}\text { Loss of beat-to- } \\
\text { beat variation }\end{array}$ & $38.6 \pm 0.7$ & $110.4 \pm 48.1^{1}(8)$ & $50.7 \pm 7.2^{1}(16)$ & 17 & $6.6 \pm 0.6^{1}(20)$ & $53.0 \pm 15.7(7)$ & 7.28 \\
\hline Late decolerations & $40.7 \pm 0.9$ & & $111.4 \pm 22.3^{1}(8)$ & 22 & $6.5 \pm 0.6^{1}(8)$ & & \\
\hline
\end{tabular}

'Significantly different from normal $(P<0.01)$ according to Student's $t$-test.

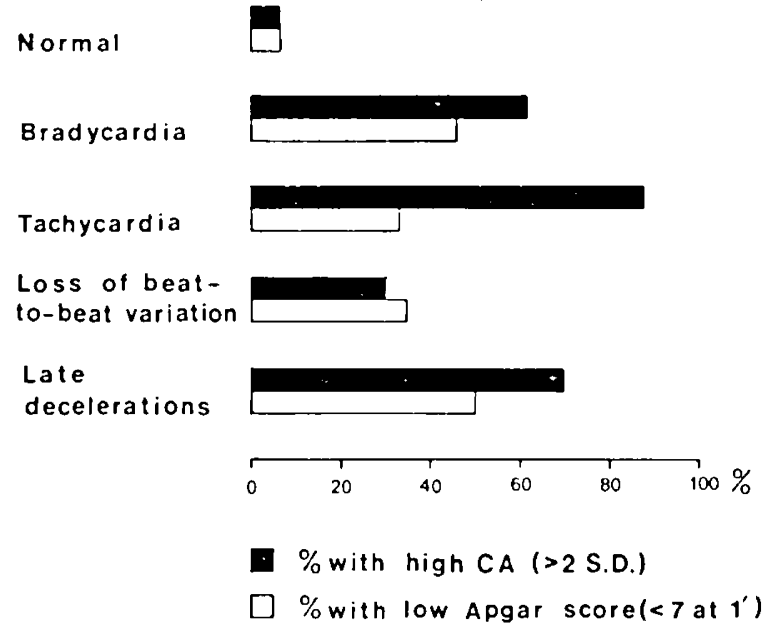

Fig. 3. The percentage of infants with high catecholamine concentrations $(C A>2 S D)$ in umbilical arterial and/or venous blood in the groups classified according to predominant fetal heart rate pattern. The percentage of infants with Apgar score less than 7 at $1 \mathrm{~min}$ in these groups is shown by white bars.

Table 3. Previously published determinations of catecholamine concentrations in blood (nanomoles per liter)

\begin{tabular}{lccc}
\hline & Arterial & Venous & Reference \\
\hline Resting adults & 3.2 & 2.5 & $(26)$ \\
Men during exercise & & 11.9 & $(26)$ \\
Women during delivery & & $5.9^{1}$ & $(13)$ \\
Normal infants $(1-36$ hr) & 16.4 & & $(5)$ \\
$\begin{array}{l}\text { Normal infants at deliv- } \\
\text { ery }\end{array}$ & 9.51 & $6.5^{1}$ & $(13)$ \\
$\begin{array}{l}\text { Asphyxiated infants at } \\
\text { delivery }\end{array}$ & $252.0^{1}$ & $6.3 .9^{1}$ & $(13)$ \\
\hline
\end{tabular}

${ }^{1}$ Plasma pressors assayed by a biologic method.

amine in the fetus (24). (3) The arteriovenous difference was found to be about 2-fold in the normal group, which strongly indicates the fetal origin of most of the catecholamines in the infant blood.

The catecholamine level in both the arterial and venous umbilical blood was remarkably high, even after uncomplicated vaginal deliveries, compared with adult values (Table 3 ). Our values for uneventfully delivered newborn infants are higher than reported previously (Table 3 ), in spite of our more strict criteria of uneventfulness. That difference could be because blood was not collected until a few hours after birth. when the amine levels probably had decreased (5). or because the plasma pressors determined by a bioassay (13) might be less specific than a fluorimetric method; a number of endogeneous substances are released at birth which may interact with a bioassay.

The high amine values found after uneventful deliveries indi- cate that the infant. even during completely uncomplicated conditions. is considerably distressed at birth. The catecholamine levels are far above the resting amine levels in adults; even adults performing heavy exercise do not reach the same level as the normally delivered infants (26). Uneventfully delivered infants have been found to have hypercapnia, increased lactate concentrations, and oxygen debt immediately postpartum, indicating that some degree of asphyxia is a normal state at birth (25). Even if special care was taken to clamp the umbilical cord immediately at birth, the infants had usually been partially cooled and activation of the sympathoadrenal system due to the cooling of the infants could not be completely avoided $(9,25)$.

Elective cesarean section would be expected to cause less catecholamine secretion; but no significant difference between these and vaginal deliveries was found. However, it is possible that the distress caused by the operation and anesthesia changes the uterine blood flow and decreases the oxygenation of the fetal blood, which could trigger amine release (see below). Infants delivered by cesarean section were found to have lower pH than those delivered vaginally (18).

Extremely high catecholamine concentrations were found in some of the asphyxiated infants, particularly those who suffered from intrauterine asphyxia just before birth. like the breechdelivered infants. The aminc levels could be compared with what is found in pheochromocytoma patients (26). However, some infants with low Apgar score had unexpectedly low amine concentrations. One possible explanation is that they suffered from intrauterine hypoxia for a long time and that their amine stores were partially released (12). In particular, preterm infants responded with less amine secretion during asphyxia compared with full term infants. The sympathoadrenal system might not be completely developed in these infants. This assumption is supported by the finding of less catecholamine secretion in the urine of preterm infants who develop apneic spells (17).

All four types of fetal heart rate patterns studied were associated with significantly increased catecholamine levels compared with those in fetuses with normal patterns. The intriguing questions are: (1) to what extent is the catecholamine level related to the fetal heart rate variation and (2) are the increased amine output and abnormal cardiotocographic patterns independent symptoms of fetal distress?

Bascline changes were associated with considerably increased catecholamine concentrations. These concentrations have been found to induce first bradycardia, probably of reflexogenic origin, and then tachycardia in both fetal sheep (21) and human neonates (16).

Late decelerations are asumed to be caused by a direct effect of hypoxia on the fetal myocardium (14). It can be speculated that increased sympathotonus augments the oxygen consumption in the fetal heart which contributes to the development of heart block and transient bradycardia. It is interesting that the same ECG pattern was seen after administration of isoproternol as after mild hypoxia in fetal guinea pigs (22).

Loss of beat-to-beat variation was associated with relatively lower catecholamine levels in the umbilical blood. Loss of beatto-beat variation might be due to decreased brain stem activity, 
which probably also is associated with decreased sympathoadrenal activity.

Thus, both clinical and cardiotocographic signs of fetal hypoxia were associated with considerably increased catecholamine output.

Holden et al. (13) found a better correlation between low pH and amine secretion than between low $\mathrm{pO}_{2}$ and catecholamines and proposed that the acidosis triggers the amine release. Even if we have confirmed their findings to some extent, we believe that the amine release is triggered by the hypoxia. $\mathrm{pO}_{2}$ is quickly reversible and the intermittent periods of hypoxia during the uterine contractions might be sufficient to cause amine release. In various animal experiments, isolated hypoxia was found to be a strong stimulus for amine release. whereas isolated acidosis or hypercapnia was less effective $(3,8)$.

The origin of the enormous amine concentrations in the blood is not known. The predominance of noradrenaline indicates that the paraganglia are involved. Hypoxia seems to deplete the paraganglia before the adrenal glands in animal experiments (3, 12).

The functional role of the enormous amine release during asphyxia in the fetus is intriguing. Probably it is of importance to sustain both the circulatory and metabolic homeostasis of the fetus (11). The noradrenaline can be assumed to effectuate the "diving" reflex in the fetal shunting of the blood between the heart, placenta, and the brain to save oxygen (23). Injection of noradrenaline in fetal rabbit can prolong the electrocortical response considerably (2). The stimulating effects of catecholamines on breathing might also be of importance for initiation of the breathing in air (cf. Reference 17).

\section{REFERENCES AND NOTIS}

1. Beard, R. W., Filshie, G, M., Knight, C. A., and Roberts, G. M.: The significance of the changes in the continuous fetal heart rate in the first stage of the labour. J. Obstet. Gynaceol. Commonw., 78: 86.5 (1971).

2. Boëthius, J., Brundin, T., and Persson, N. $\AA$.: The effect of moradrenaline on the direct cortical response of asphyxiated newborn rabbits. Acta Physiol. Scand., 76: 15A $(1969)$.

3. Brundin, T.: Studies on the preaurtal paraganglia of newborn rabbits. Acta Physiol. Scand., 70: Suppl. 290 (1966).

4. Chang, C. C.: A sensitive method for spectrophotofluorometric assity of catecholamines. Int. J. Neuropharmacol.. 3: 643 (1964)

5. Check, D. B., Malinek, M., and Fraillon. J. M.: Plasma adrenaline and noradrenaline in the neonatal period, and infants with respiratory distress syndrome and placental insufficiency. Pediatrics, 31 : 374 (1963).

6. Cibils, L. A .: Clinical significance of fetal heart rate patterns during labour, 11 . Late decelerations. Amer. J. Obstet. Gynecol.. 123: 473 (1975).

7. Comline, R. S., and Silver, M. R.: The release of adrenaline and noradrenaline from the adrenal glind of the foetal sheep. J. Physiol. (Lond.), 156 $424(1961)$.

8. Comline R. S., Silver, 1. A., and Silver, 11.: Factors responsible for the stimulation of the adrenal medulia during asphyxia in the fetal lamb. J.
Physiol. (Lond.). 178: 211 (1965).

9. Dawes. G. S.: Foctal and Neonatal Physiology (Yearbook Publishers. Chi(ago. 1968)

1(). Dubowitz, L.. Dubowtiz, V., and Goluberg. C.: Clinical assessment of gestational age in the newborn infant. J. Pediat. 77: 1 (1970).

11. Friedman. W. F.: The intrinsic physiological propertice of the developing heart. In: W. F. Friedman, M. Lesch, and IE. H. Sonnenblick: Neonatal Heart Discase, p. 21 (Grune \& Stratton, New York, 1973).

12. Hervonen, A., and Kurkola, $O$.: The effects of hypoxia on the catecholamine content of human fetal abdominal paraganglia and adrenal medulla. Acta Obstet. Gynecol. Scand., 51: 17 (1972)

13. Holden, K. R., Young, R. B., Piland, J. H., and Hurt, W. G.: Plasma pressors in the normal and stressed newborn infant. Pediatrics, 49: 495 (1972).

14. Hon, E. H.: The classification of fetal heart rate. Obstet. Gynecol., 22: 137 (1963).

15. Jomes, C. T., and Robinson, R. O.: Plasma catecholamines in foctal and adult sheep. J. Physiol. (Lond.), 248: 15 (1975).

16. Karlberg, P. Mloore, R. E... and Oliver. T. K.: Thermogenic and cardiovasculat responses of the newborn baby to noradrenaline. Acta Paediat. Scand. 54: $225(1965)$.

17. Kattwinkel, J., Mars, H., Fanaroff, A. A.. and Klaus, M. H.: Urinary biogenic amines in idiopathic apnea of prematurity. J. Pediat., 88: 1003 $(1976)$.

18. Kjellmer, I., Magno, R., and Karlsson, K.: Anesthesia for cesarean section. I Acta Anesthesiol. Scand. 18: 88 (1974).

19. Nuwayhid, B., Brinhman, C. R., III, Su, C., Bevan, J. A., and Assali, N. S. Development of autonomic control of fetal circulation. Amer. J. Physiol., 228: 3.37 (1975).

20. Ott, W. J.: The current status of intrapartum fetal monitoring. Obstet. Gynecol. Surv.. 31: 339 (1976).

21. Rithcic, J. W. K.: The endocrine, metabolic and cardiovascular effects of catecholamines in the sheep fetus. (M.D. thesis, Oxford, 1975)

22. Rosén, K. G.. Hökegi̊rd, K. - H... and Kjellmer, I.: A study of the relationship between the electrocardiogram and hemodynamics in the fetal lamb during asphyxia. Acta Physiol. Scand.. 93: 59 (1975).

23. Rudolph. A. M... and Heymann. M. A.: Control of foctal circulation. In: K. S. Comline, K. W. Cross, G. S. Datwes, and P. W. Nathaniclsz: Foetal and Neonatal Physiology, p. 89-111 (Cambridge University Press. Cambridge. $1973)$.

24. Saarikoski. S.: Fate of noradrenaline in the human foetoplacental unit. Acta Physiol. Scand.. 93: Suppl. 421 (1975)

25. Tunell, R.. Copher, D., and Persson. B.: The pulmonary gas exchange and blood gas changes in connection to birth. In: J. B. Stctson and P. R. Swyer: Current Concepts of Neonatal Intensive Care, p. 89) (Warren H. Green, Inc.. St. I ouis, 1976).

26. Vendsalu, A.: Studies on adrenaline and noradrenaline in human plasma. Acta Physiol. Scand. 49: Suppl 173 (1960)

27. Wollingford. Conn.

28. Brockmann activity II, BDH Chemicals Lid., Poole, England.

29. Sliver Spring, Md.

30. Copenhagen, Denmark.

31. We want to thank M1rs. Ingrid Dathlin for excellent technical help; Dr. Ragnar Tuncll and Dr. Nils -Olov Luncll for valuable criticism; and the midwives at the delivery ward, Huddinge Hospital, for their assistance

32. This research was supported by Ahlen Stiftelsen, Expressen's and Odd Fellow's Prenatalforskningsnämnd Stiftelsen Samariten, and the Swedish Nedical Research Council (1378-19X-(15234-(1)1).

33. Requests for reprints should be addressed to: H. Lagercrantz, M.D.. Department of Pediatrics, Huddinge Hospital. S-141 86 Huddinge (Sweden).

34. Received for publication December 29, 1976.

35. Accepted for publication February 2, 1977. 